\title{
Rise and Resolution of Ethnic Conflicts in Nuremberg Neighbourhoods
}

\author{
Claudia Köhler
}

This chapter is based on case studies carried out in three neighbourhoods of the German city of Nuremberg. ${ }^{1}$ In the next pages, the general focus of this book on inter-group relations at neighbourhood level is combined with a more specific thematic focus on inter-group conflict. This choice is meant to illustrate and deepen the general understanding of integration as a form of 'discordant harmony' which inspires all the essays contained in this volume (see chapter "Introduction"). Through a detailed analysis of processes of emergence, development and settlement of neighbourhood conflicts in two neighbourhoods (Werderau, Langwasser) - contrasted against a case where peaceful interethnic relations prevail (Gostenhof) - this chapter shows the ambivalent nature of neighbourhood-level interethnic conflict,

\footnotetext{
${ }^{1}$ Besides the general methodological features of the studies collected in this volume, and illustrated in the Introduction and in the Methodological Annex, the Nuremberg case studies were based on the following mix of research tools:

Ethnographic interviews were the primary instrument. A total of 34 interviews were conducted with residents of each neighbourhood. The interviewees were chosen on the basis of a sampling method aimed at giving qualitative representation to the different groups of society in rough proportion to their distribution in each neighbourhood. The sampling criteria included: migration background (direct, indirect, none), gender, age (18-35, 36-65 and 65+ years), and participation in social life (none/low, user of measures/activities, conductor of measures/activities). The interviews were conducted in German, with the exception of two interviews in Turkish, between October 2011 and January 2012.
}

Expert interviews were conducted with 12 stakeholders and policy makers between March and April neighbourhood 2011.

Policy and stakeholder interviews were conducted with eight people with specific policy expertise on one or more of the target neighbourhoods between October 2011 and January 2012.

Quantitative socio-demographic and economic data was collected for relevant dimensions and a neighbourhood forum was conducted in the Werderau neighbourhood in March 2012.

C. Köhler $(\bowtie)$

European Forum for Migration Studies (EFMS), University of Bamberg, Bamberg, Germany

e-mail: claudia.koehler@uni-bamberg.de 
which can certainly disrupt but also ultimately promote inter-group relations depending on a plurality of factors among which an important role is played by the capacity and will of local policy communities to interpret, face and manage conflicts.

Before starting our analysis of specific cases of inter-group conflict (or lack thereof), we will first illustrate some essential figures on Nuremberg's migration history and the key features of the three target neighbourhoods, which justify their selection as case studies.

With slightly more than half a million inhabitants, Nuremberg is the second largest city in the Land of Bavaria. Its total population has increased by about $25 \%$ $(100,000$ people) in the last 55 years. At the same time, the proportion of foreign inhabitants has risen sharply. While foreigners constituted $2 \%$ of the total population in 1956, their proportion in 2012 amounted to $18 \%$. But if we take a wider look at immigrants and their descendants, irrespective of nationality, almost $40 \%$ (38.8) of Nuremberg's population can be identified as having a migration background (Statistik Nürnberg Fürth 2011a, b, 2012).

In 2009 , the migratory inflow to Nuremberg was around 30,000 with an immigration rate of $5.7 \%$ and a migratory balance rate of 0.02 ; the annual outflow has been around 28,000 per year since 2000 (Statistik Nürnberg Fürth 2011a: 32-34). Fifty nine per cent of migrants arrived in the last 5-10 years. Migrants and foreigners have mainly settled in the downtown and surrounding areas. In most statistical sectors of those areas, foreigners constitute between $15 \%$ and $30 \%$ or more of the total population, while in most statistical sectors of the northern, southern and eastern areas of Nuremberg, the proportion of foreigners is $10 \%$ or less (Statistik Nürnberg Fürth 2011a).

The largest groups of foreigners are from the EU (35\%; mainly from Greece, Italy, Poland and Romania) and from Turkey (23\%), followed by Ukraine, Russia, Croatia, Bosnia-Herzegovina and Iraq (Statistik Nürnberg Fürth 2011c). The distribution of foreigners across the statistical sectors and the location of the statistical sectors of Nuremberg are illustrated in Fig. 1.

Of the two neighbourhoods selected as arenas of manifest neighbourhood conflicts, Werderau was also chosen because of the particularly strong increase in foreign population over the last decade and its above-city-average share of foreigners (27\% in 2009) (Statistik Nürnberg Fürth 2011a). Foreigners and residents with a migration background in Werderau primarily originate from Turkey and in lesser numbers from Italy. As we will see in much greater detail, the conflict process that we researched in this neighbourhood evolved around the sale of housing allotments leading to a migration into and out of the neighbourhood. The consequent change in the composition of the neighbourhood's population caused serious tensions at different levels which were explicitly framed by important local actors in ethnic terms. Our analysis focuses on the structure of this conflict and on subsequent developments in inter-group relations in the neighbourhood.

As shown below in Fig. 2, the residential part of Werderau is classified as a 'hardly socially challenged' 'residential areas for families with children' (Social space type 5) according to the official social space analysis of the city of Nuremberg (Statistik Nürnberg Fürth 2010). 


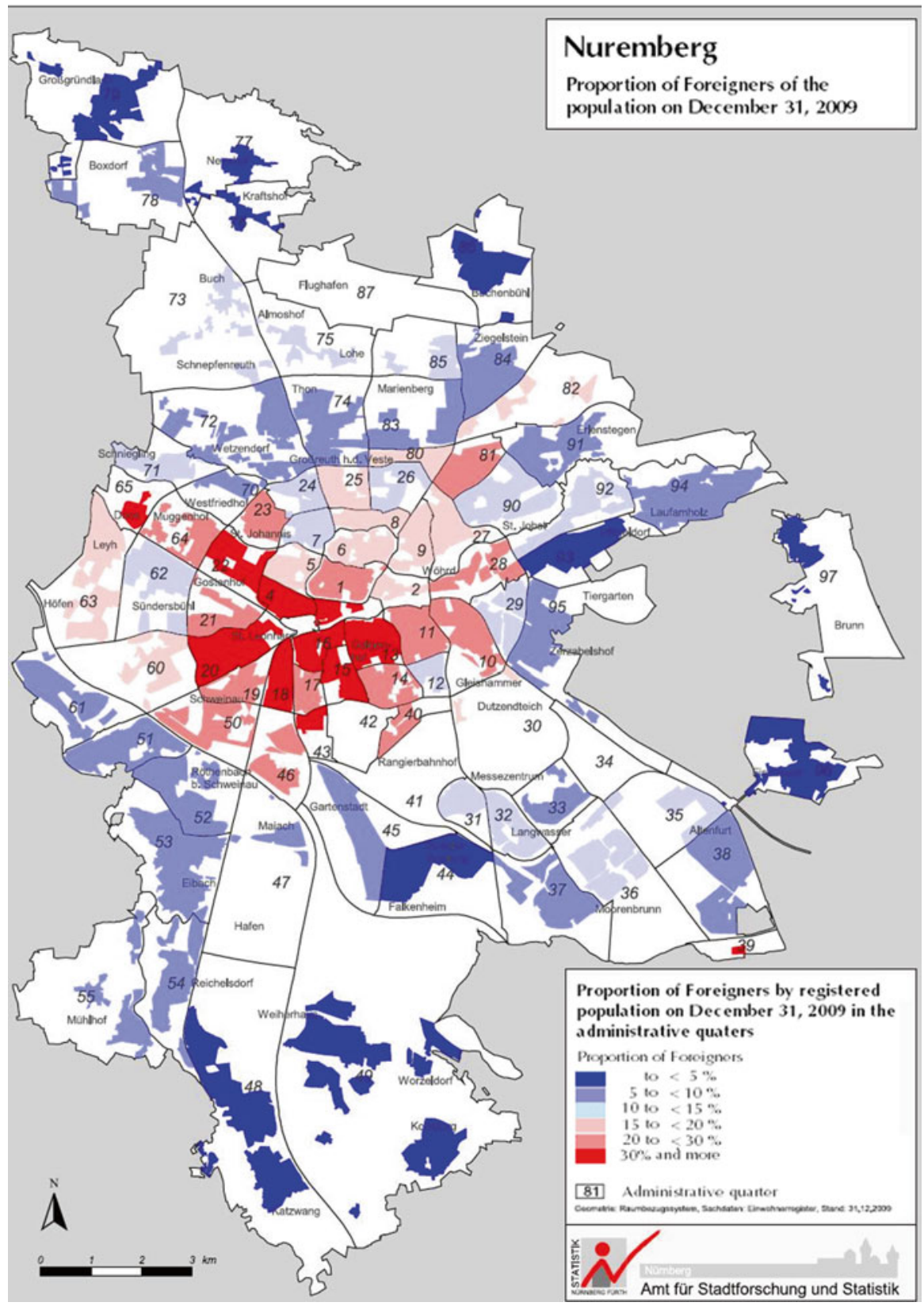

Fig. 1 Proportion of foreigners in the statistical sectors of Nuremberg, 2009

The Langwasser neighbourhood was primarily selected as the arena of a neighbourhood conflict that evolved in a residential area affected by the project to create an Intercultural Garden. The project aimed at fostering inter-group relations and 

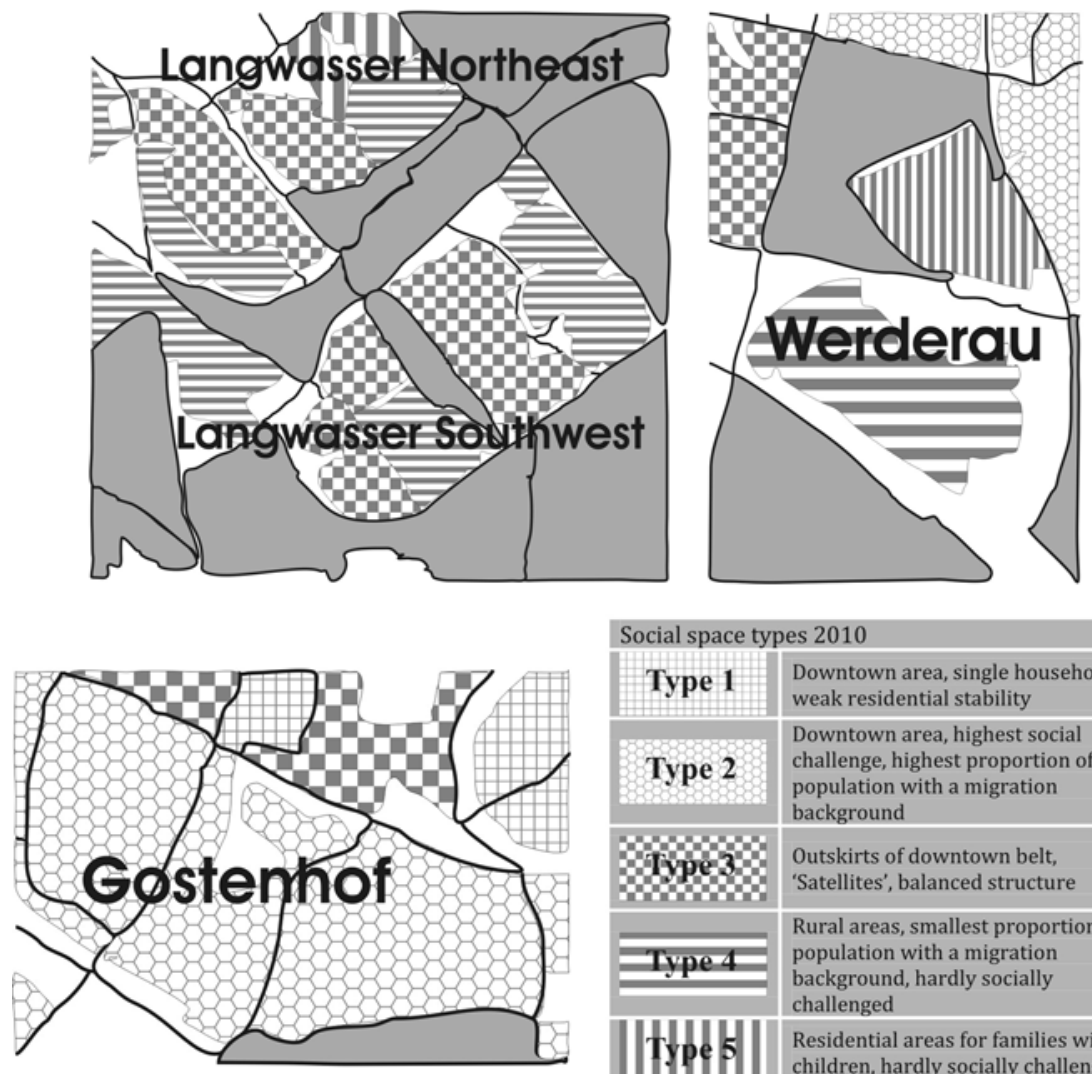

\begin{tabular}{|c|c|}
\hline \multicolumn{2}{|c|}{ Social space types 2010} \\
\hline Type 1 & $\begin{array}{l}\text { Downtown area, single households, } \\
\text { weak residential stability }\end{array}$ \\
\hline no & $\begin{array}{l}\text { Downtown area, highest social } \\
\text { challenge, highest proportion of } \\
\text { population with a migration } \\
\text { background }\end{array}$ \\
\hline & $\begin{array}{l}\text { Outskirts of downtown belt, } \\
\text { 'Satellites', balanced structure }\end{array}$ \\
\hline & $\begin{array}{l}\text { Rural areas, smallest proportion of } \\
\text { population with a migration } \\
\text { background, hardly socially } \\
\text { challenged }\end{array}$ \\
\hline & $\begin{array}{l}\text { Residential areas for families with } \\
\text { children, hardly socially challenged }\end{array}$ \\
\hline & Not included in the typification \\
\hline
\end{tabular}

Fig. 2 Social space types in Nuremberg, 2010 (Statistik Nürnberg Fürth 2010)

integration but in its initial phase it led to conflicts along ethnic and origin lines. Thematically, our focus will not be on the project itself, but on the ways in which it was perceived by the residents of the area and on the influence of third parties on local conflict dynamics. Spatially, the focus is on the area surrounding the garden project.

The choice of Gostenhof as a specific area of investigation originates from the high diversity of its residents which shapes the whole neighbourhood, and from the absence of manifest conflicts in spite of such a high level of diversity. Gostenhof is one of the city's neighbourhoods with the highest and most rapidly increasing shares of foreign population (39 \% in 2009) (Statistik Nürnberg Fürth 2011a). This is reflected in the official classification of the whole area as a social space type 2 which stands for 'downtown area, highest social challenge, highest proportion of population with a migration background' (see Fig. 2). The area around the neighbourhood's main street (Gostenhofer Hauptstrasse) is characterized by an even more pronounced diversity. This area was chosen as an interaction site in order to analyze inter-group relations in a context of high diversity. 
While two of the selected neighbourhoods entirely coincide with one statistical sector (no. 46 for Langwasser, no. 4 for Gostenhof), Langwasser - by far the largest of the three - stretches over four statistical sectors (nos. 32, 33, 36 and 37). For the purposes of our analysis, we assume that statistical sectors can be considered as 'neighbourhoods' and we will refer to them as such throughout the chapter. As a matter of fact, Nuremberg statistical sectors usually correspond with socially perceived neighbourhood boundaries, as is evident from the ethnographic analysis. An exception to this is Langwasser where, as just explained, the neighbourhood consists of four distinct statistical sectors, corresponding to its northern, southern, eastern and western parts.

\section{Ethnicization of Neighbourhood-Level Conflicts}

The analysis in Nuremberg placed a particular focus on the development of and underlying reasons for conflicts in neighbourhoods which, at first sight, appear to be migrant-native or interethnic conflicts.

In the tradition of inter-group relations research, conflict can be defined as strife between two (or more) groups for the control of goods that each urgently desires, but which can be attained by one group only at the expense of the other(s) (Sherif and Sherif 1969: 239). Goods may be material goods and rights, but also values, beliefs, norms and lifestyles.

We identified such conflicts in Werderau and Langwasser and in the next pages we will reconstruct the details of the development, the different stages and the solutions of these cases of neighbourhood conflicts. A descriptive approach has been combined with a theoretical analysis. The latter is based on elements of inter-group relations theory (Sherif and Sherif 1969) and a reformulation of Esser's theory of interethnic conflict (Esser 2000: 418-423).

The basic theoretical proposition we work with is that there is no 'genuine' interethnic conflict. Conflicts of the type analyzed in the two researched neighbourhoods arise from a 'structural conflict' of interests and are framed as ethnic conflicts in a series of stages. Based on Esser's (2000) model and slightly reformulating it, we have distinguished the following stages of conflict development that we will apply to explain the conflicts in Werderau and Langwasser.

- Development of the structural conflict: Structural conflicts can have both a material and a cultural dimension. On the material side, opposite interests collide with each other whereas on the cultural side different modes of behaviour and different values and rules compete.

- Framing and ethnicization of the conflict: In the stage of the framing of the conflict, a definition is formed of the situational context in which people can be mobilized over a conflict. The main ways in which structural conflicts can be defined are along cleavages of class, ethnicity and religion. The framing of a situation has important implications: it is a process in which individuals change their perspective from an individual-rational orientation to a collective-emotional 
orientation. This may take the form of an ethnic identification or of religious or other Gemeinschaft-like framing of the situation with feelings of collective solidarity (Esser 2000: 420). Ethnicization implies that the conflict is defined as group conflict, hence boundaries are being constructed: we and they, Germans and Turks. Ethnicization brings into play existing stereotypes about the groups that help to intensify the conflict, even though they have nothing to do with the structural conflict.

- Mobilization and intensification of conflict: Ethnic framing has a strong emotional component and increasingly drives people on both sides to take part in the conflict. Such mobilization can be further increased by outside intervention.

- Solution of conflict: Conflicts can be solved in different ways: by compromise between the parties, mediation, mutual exhaustion of the parties or by one side winning over the other. At this stage, the integration process can resume in a more constructive direction.

\section{Village-Like Lifestyles Within the City: Werderau}

The structure and lifestyles of Werderau, strongly reminiscent of a village, have historically had a profound influence upon the development of inter-group relations in the neighbourhood and continue to do so. The analysis of this development in the next section is combined with the analysis of the identified conflict and is structured in line with the conflict stages illustrated above. The following sections discuss the role of places and of organized collective action in inter-group relations as well as group formations and boundary-making in the neighbourhood (Fig. 3).

\subsection{Are Migrants to Blame for the Neighbourhood Conflict?}

\section{Early Characteristics of the Neighbourhood Are Setting the Stage for the Development of a Structural Conflict}

The Werderau conflict is related to characteristics of the neighbourhood which arose with the very foundation of the settlement shortly before World War I. In 1911 a non-profit association was formed and the construction of houses began for the new settlement. The MAN company - a producer of cars and car parts - and a house building cooperative of MAN workers were the shareholders of the association. Employment in the factory was a precondition for renting a house; therefore, the Werderau population consisted of MAN workers and their families. Situated outside the city, the neighbourhood had a rural character and the appearance of a village. Each house had a garden. The MAN workers' council played a central role in community life. In sociological terms, Werderau matched Ferdinand Tönnies' classical definition of a Gemeinschaft. An interviewee even went as far as to describe the neighbourhood of these early days as 'an island of the saints'. 


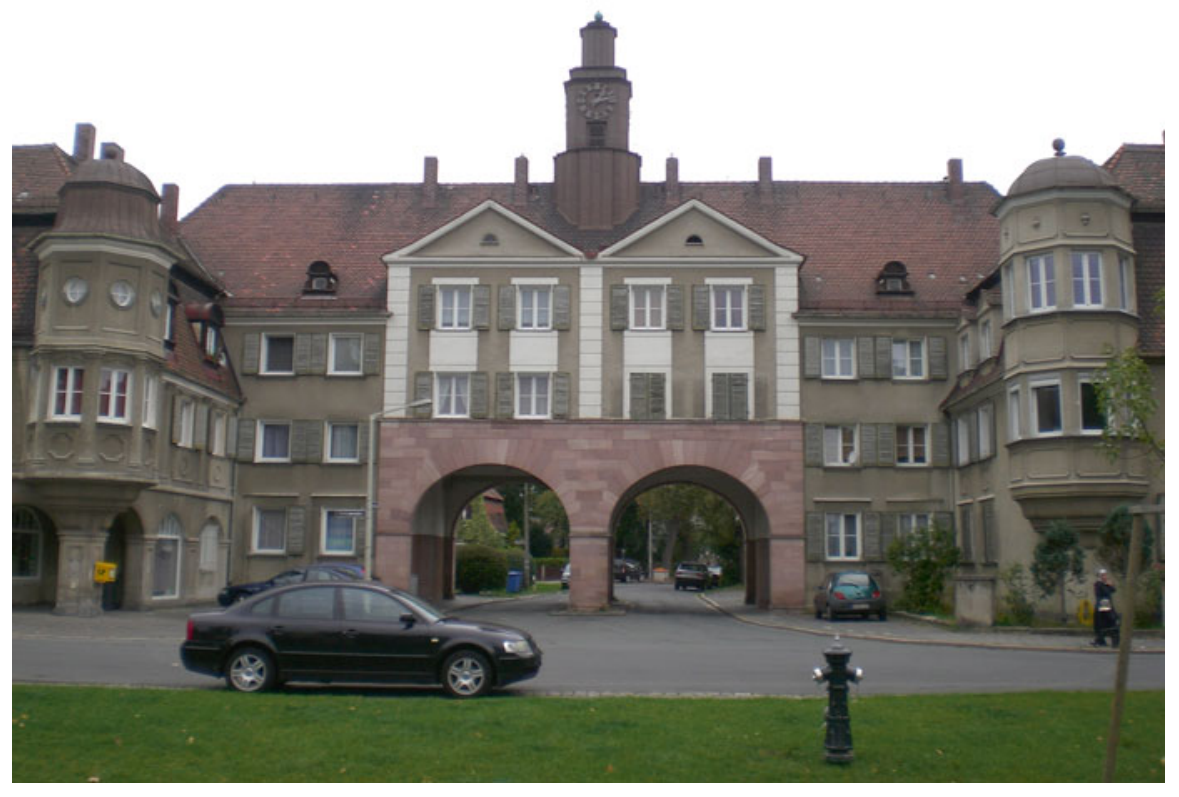

Fig. 3 Main square of Werderau (Photo by L. Batrla)

In 1941 the workers' housing cooperative was dissolved and the MAN company remained as the single owner of the settlement and the houses. In the 1950s additional houses were built, some without gardens. New MAN workers moved in and enlarged the population. The MAN workers' council had a strong position; it ruled over housing and living conditions, took the decision on who was eligible to move into the neighbourhood, organized leisure time activities for residents and regulated disputes among the tenants.

The 1960s saw the construction of a large multi-storey building with single apartments in addition to the existing one and more family houses which characterized the neighbourhood. A number of the guest workers recruited by MAN from the 1960s on, most of whom were from Turkey and some from Italy, moved to the neighbourhood and became part of the Werderau population. Later on, their families followed. These migrants were seen as colleagues and neighbours and were well-integrated.

The idyllic character of the neighbourhood was somewhat disturbed in the 1970s, when a motorway was built close to it. Whereas this environmental issue could be settled by the construction of anti-noise and anti-pollution walls, a very different kind of issue developed in 1990, which would become a major cause for the Werderau conflict: the Werderau building company that owned the houses abolished its non-profit status. One of the consequences was that people other than MAN employees were allowed to rent Werderau houses. The other consequence was that 
severe fears arose among residents that the MAN-controlled building company would sell the houses to outside investors and that their housing rights and low rents were threatened.

These fears were realized in 1998 when MAN sold their housing stock to the real estate company Telos. With the new owners, the MAN workers' council's influence on housing and living conditions in Werderau ended. Telos aimed at reselling the housing area as a whole or by single houses and started forcing some tenants to move out and reselling the houses. New tenants and new owners moved into Werderau, mainly migrants of Turkish origin.

In 2001, Telos went bankrupt and a series of ownership changes among different investors occurred, in which more houses were sold to single households and new inhabitants came to Werderau, again mostly of Turkish origin.

On the material side of the structural conflict, we find the opposing interests of investors and of old inhabitants. The old inhabitants wanted to keep their housing rights (the right to life-long residence, low rent, some control over who moves into the neighbourhood), while the different waves of new owners wanted to pursue their interests as investors, e.g., reselling the houses. Regarding the cultural dimension of the structural conflict we find that the new inhabitants had different patterns of behaviour and the old inhabitants felt that the new neighbours were not 'keeping to the rules' (noise, garbage, children's behaviour). Hence, boundaries were constructed along cleavages of the time of residency in the neighbourhood whereby these partly overlap with ethnic cleavages: new residents are often migrants, many of them of Turkish origin, whereas old residents are natives and migrants of mainly Turkish and Italian origin.

\section{Framing and Ethnicization Leads to the Definition of the Conflict as Group Conflict Between Germans and Migrants}

The framing of the structural conflict in Werderau took place along ethnic lines. The incoming new residents were perceived as threatening the established residential status of old Werderau inhabitants and as endangering the old order in the neighbourhood. The structural conflict was ethnicized as a group conflict between Germans and migrants, primarily Turkish ones.

One interviewee describes the perception of old-established German residents as follows:

The Turks are now buying the neighbourhood of Werderau and are destroying our beautiful old culture and our cooperation. (Werderau, children caregiver, 40 years old)

Another interviewee went on to explain:

They [old-established Germans] considered this as a hostile take-over. They complained about another culture coming in. Up until then it used to be normal that everything went by our [old-established Germans] rules. All of a sudden everything changed. (Werderau, resident, 53 years old) 
Whereas old-established residents seemed not to mind new migrants (of Turkish origin) in the neighbourhood in general, the larger numbers of them moving in within a short period of time led to growing worries on their behalf:

Some people have a different perception of life than me, and the more there are of them in my neighbourhood, the more I separate myself from them. (Werderau, resident, 61 years old)

The Turks in our building are really cool, but there are just too many of them here [in the neighbourhood], they don't belong here. (Werderau, resident, 53 years old)

However, not only migrants of Turkish origin were involved in this process. Besides small numbers of migrants of different origins, a considerable number of those originating from Italy were involved as well. But taking account of the fact that Turkish migrants represented by far the largest group among migrants in the neighbourhood, the terms 'migrant' and 'Turk' appeared to be used interchangeably in the framing of the conflict.

\section{Outside Intervention Intensifies the Conflict Mobilization Process}

Stereotypes about Germans and Turks were brought into play, even though they had nothing to do with the actual conflict, leading to intensification of the conflict. This in addition to the ethnic framing with strong emotional components, drove more and more people to become involved in the conflict. This mobilization process was further increased by outside intervention in 2002: the mobilization and intensification of the conflict was mirrored in the fast growing media coverage of Werderau, increasingly portrayed as a 'problematic neighbourhood'. The ethnicization of the conflict had already been partly stimulated by nativist right-wing forces of the neoNazi party NPD and a regional group called 'Ausländerstopp'. They claimed to be supporting the old inhabitants' interests and blamed migrants for driving people out as tenants, selling the houses to mostly Turkish families and threatening the 'old order' of the neighbourhood. Inhabitants of the neighbourhood felt addressed through this narrative since many of them felt neglected by the city administration of Nuremberg which did not seem to care about what was happening in the neighbourhood. The media coverage was particularly concerned with the high shares of votes for NPD by Werderau residents which was recorded in the same period. This has to be understood against the background of Werderau residents being used to being taken care of by the MAN company and the workers' council in the past. No alternative structures, such as a strong policy community, active civil society groups had been put in place after the demise of these structures.

\section{Political Change and Mediation Lead to Conflict Solution}

In 2002 a new mayor was elected and the Social Democrats became the leading political force in Nuremberg. The new administration installed a district coordinator in the neighbourhood who initiated a round table of citizens and voluntary 
associations which led to the start of communication between the conflict groups. A citizens' association was founded. The conflict, which had not been violent anyway, started de-escalating. After 2 years, in 2004, the district coordinator could be withdrawn from the neighbourhood. In the same year a youth centre was opened which partly took over some of the functions of the district coordinator.

After several changes in the ownership of the Werderau housing association, in 2008, the remaining property - houses that had not been sold to outside families was bought by the non-profit city housing company WBG. This led to a further calming of the situation in the neighbourhood. However, major changes in property ownership had already taken place. Therefore, the remaining property taken over by WBG and the impact of this change of ownership on inter-group relations in the neighbourhood was not very significant.

As a result of the many changes in the neighbourhood in the last decade, the old working class village-like Gemeinschaft no longer exists. Divisions and ethnically based distinctions persist but disputes between the groups have eased and they have learned to communicate and respect one another. The city continues to support stakeholders in their community work. On this basis, the integration process in the neighbourhood can resume on a more positive path.

\subsection{The Double Nature of Space in Werderau: Connecting Potential and Subject of Dispute}

The arrangement of housing in a village-like shape with small garden units connected to each building provides plentiful opportunities for residents of various groups, to interact, e.g., on the main square and in their gardens. Additionally, the fact that all the people living in the neighbourhood used to be (and many still are) employees of the nearby MAN factory meant that they met each other on their way to work on a daily basis. This enabled intensive and stable contacts. The small gardens around the apartment buildings, which are part of the neighbourhood's villagelike structure, are a point of shared interest for residents and provide further opportunities for interaction. At one point in time, as seen above (Sect. 2.1), housing in Werderau became a source of considerable inter-group tensions; recent years, however, have seen a clear improvement in neighbourly relations.

Besides housing, the areas related to shopping activities seem to offer potential for connection in Werderau. Due to the limited number of shops in the neighbourhood, it is unavoidable that people will meet. However, people have lately been making increasing use of the larger shopping malls in the uninhabited part of Werderau, leading to a decrease in interactions on the street.

Obviously, shared interests carry the potential of bringing people together. In this sense the school, as the place where people share an interest in the education and well-being of their children, emerges in Werderau as a relevant place for positive and frequent inter-group relations. People, especially mothers, of different origins meet in and around the school and discuss issues related to their children. These 
encounters are experienced primarily in a positive way. At the same time, a lack of space where people, especially young people, who share similar interests, can come together has been identified in the neighbourhood. A youth centre with very limited space and an unsecured future existence is the only such place in Werderau and does not have the potential to meet the needs of the whole neighbourhood.

\subsection{Group Relations in Werderau: Who Do People Associate with?}

In Werderau, with foreigners making up $27.2 \%$ of the total population in 2009 (Statistik Nürnberg Fürth 2011a), in residents' perception and relations we find the main cleavages between ethnic majority and minorities as well as along lines of age and length of stay.

Most residents with a migrant background are of Turkish origin, with a smaller group of migrants with Italian origins. In this context, the main cleavage is between a majority made up of native German residents and residents with Turkish and Italian origins. The minority group is sometimes referred to in a unitary way as 'the Turks' and sometimes as 'foreigners' by the majority. Neither term is correct primarily because a large share of the population with a Turkish background has acquired German citizenship and/or were born in Germany and thus are not foreigners. Furthermore, residents of Italian origin are frequently included among 'the Turks'.

Moreover, we find cleavages not only between minority and majority, but also within minority groups. In the case of Werderau, there appears to be a division between residents with a Turkish background who have recently arrived in the neighbourhood and are more traditionally oriented in religious matters, and those who have been living there for a longer time and take a more secular approach to religion. The criteria of length of stay and religion will be the subject of further discussion below.

Regarding the relevance of age groups, we find that intergenerational cleavages overlap with majority-minority cleavages in Werderau: elderly long-established residents of German origin blame young 'Turkish' people in the neighbourhood for not sticking to the 'old order', e.g., by making noise, not taking care of the neighbourhood properly, etc. However, the group they are referring to is not exclusively of Turkish origin, although young people in the neighbourhood are indeed predominantly of Turkish origin.

In relation to intergenerational cleavages, depending on the context, we find children operating alternatively as a factor of tensions or as a bridge. In Werderau, mothers with children are identified as a group on their own. The church in Werderau organizes meeting groups for mothers with small children. These are well-attended and welcomed, regardless of the cultural and religious background of the mothers. In the daytime, mothers with small children use the playgrounds, whereas young people, in the absence of other meeting places, use them in the evening time. There 
is hardly any encounter between these mothers and representatives of older or younger generations. Children here connect mothers of different backgrounds. Their daily habits differentiate them from other groups.

Elderly Germans perceive that it is 'the Turks' who behave inappropriately in the neighbourhood. Due to the over-representation of Turkish families among the socially disadvantaged and the over-representation of youngsters of Turkish origin among young people in the neighbourhood, young people with a Turkish background are particularly over-represented in the group about whom elderly Germans typically complain more. At the same time, young people complain about the elderly being too critical towards their lifestyles:

They [the elderly] start stressing immediately and are very intolerant towards minor issues.

(Werderau, resident, 17 years old)

These complaints seem to be based on culture as well as on generation. Hence, ethnic and intergenerational boundaries are overlapping, which may lead to a reinforcement of cleavages.

During our fieldwork, religion has not emerged as a cleavage in 'everyday' intergroup relations, although it was used as a marker of ascription when conflicts arose. Although religion had not been a cleavage in inter-group relations in Werderau in the past, in the early 2000s the presumed Muslim identity of newly-arrived Turkish residents in the neighbourhood was instrumentalized, primarily by external actors (e.g., the media and right-wing groups), in order to steer the conflict between newlyarrived residents and long-established ones. As described above, these tensions were primarily about control over the housing stock and the rules and order in the neighbourhood, but were framed in ethnic and religious dimensions.

At the same time, the way in which religion is interpreted and lived sometimes also generates divisions within the same confessional group: among residents with a Turkish background in Werderau we identify a cleavage between long-established individuals who interpret Islam in a more open manner, e.g., wear no head scarves and do not attend a mosque on a regular basis, and the newly-arrived who tend to stick to a more traditional way of understanding and living Islam. The two groups appear to have hardly any contact.

As for length of stay, we found it operating both as a bridging factor and as a boundary. This applies to the residents in general, but also within minorities. In the past, most residents - migrants as well as natives - had been living in the neighbourhood for a similar length of time. They perceived themselves as one group where everybody knew each other. When the composition of the population changed, cleavages between long-established and new residents appeared. As noted above (Sect. 2.1), long-established residents perceived new residents as a threat to the 'old order' and as competitors for housing stock. Since people with a migrant background were underrepresented among the long-established residents and overrepresented among the newly-arrived residents, at first sight, the division appeared to be along ethnic lines. However, the main criterion for boundary-making was 
indeed length of stay. It is also notable that the group of long-established residents complains about the present inter-group and social relations and contrasts them to an ideal-typical past, while newly-arrived residents are content with the relations in the neighbourhood.

\subsection{The Policy Community: Promoters or Disablers of Inter-group Relations?}

The main policy actor in the past used to be the MAN workers' council and the MAN building company. After their withdrawal, the present policy community in Werderau primarily comprises a citizens' association, the local church community and youth workers. In the stage of conflict resolution, a district coordinator was temporarily involved. A small migrants' organization exists but cannot be considered influential.

As a whole, the policy community in Werderau appears to be in a developing rather than an advanced stage, as for example in Gostenhof. In earlier times the policy community used to be rather weak, which can also be attributed to the small size of the neighbourhood. This former lack of a strong policy voice contributed to the neighbourhood's low resilience in the face of xenophobic approaches, whereby the conflict around the sale of housing units was framed and ethnicized. No district coordinator was in place at the time and associations were hardly present in the neighbourhood. The conflict was solved by the negotiations of a district coordinator who was temporarily placed in the neighbourhood by the City. At the same time a citizens' association and a youth centre were founded in order to permanently provide the neighbourhood's residents with a medium to voice their interests and with a meeting place, at least for the youth. After the termination of the temporary district coordination, both two organizations, together with other institutions of Werderau, have received support from the city council with their networking activities and independent advocacy of the neighbourhood's interests. The policy community is still facing challenges in Werderau and is not as strong and well-represented by associations and other actors as other neighbourhoods of Nuremberg. However, the policy community seems to be organized enough now to represent different interest groups, negotiate between different interests when necessary, and communicate neighbourhood concerns to the city level. This organizational level of the policy community, which was not in place at the time of the mentioned conflict, now seems to make the neighbourhood more resilient to potential xenophobic external influences. 


\subsection{Lessons for Werderau's Future}

Werderau is an example of a former structural conflict between investors and longtime house renters, who felt that their housing rights ( 'property rights') were under threat. The conflicts arose because of different perceptions of the rules that regulate the use of space, interactions and behaviour in the neighbourhood. Hence, the root of the conflicts was a competition in the use of place and control over housing stock, but was interpreted as an ethnic or cultural conflict. Since it was primarily families of Turkish origin who bought houses sold by the investors, it was rather easy to ethnicize and emotionalize the conflict and extend it to this group. A second dimension of property rights - the desire to have control over one's environment - was cultural and confronted old and new residents with very different values and behaviour, lifestyles and senses of order. The material side of the conflict could have been avoided or solved earlier by political intervention and by having a non-profit housing company take over the old MAN housing stock.

One interviewee puts it as follows:

The residents of these apartments should have been informed better and earlier, instead MAN and the City were keeping the plan a secret. (Werderau, resident, 70 years old)

And another one recommends:

The residents should have been given realistic chances to buy the apartments themselves.

The City should have taken better care. (Werderau, resident, 61 years old)

Earlier mediation by a community worker and/or a strong policy community might have avoided the ethnicization of the conflict and the anti-immigrant group's intervention from outside.

One interviewee describes this as follows:

After the sales [of the housing stock] the sense of togetherness should have been fostered more and politicians should have responded more to the calls for help that came out of the neighbourhood. (Werderau, resident, 61 years old)

Hence, the functioning of the policy community appears to be a key factor in avoiding conflicts and contributing to harmonious inter-group relations. The neighbourhood, with the support of the City, is now in the process of strengthening this function.

Length of stay was an important component in the positioning of groups and boundary-making within the conflict. This component not only led to divisions between long- established Germans and newly-arrived migrants with a Turkish background, but led also to the division of the group of residents with a Turkish background into those who had arrived in the neighbourhood recently and those who had been living there for a longer period of time. The latter tended to associate rather with long-established Germans. These boundaries are still visible but since the conflict situation was solved, inter-group relations have become more positive, and consequently it appears that integration processes have been enabled. 


\section{High Diversity in an Urban Structure: Langwasser}

Langwasser is an area of the city with a highly diverse urban structure. We focus our analysis on a neighbourhood within the broader Langwasser district, in which a project was initiated for the improvement of inter-group relations. In its initial phase this project led to a conflict. We will first analyze the development of this conflict following the different stages of conflict as identified in Sect. 1. The subsequent sections discuss the role of places and of organized collective action in inter-group relations as well as boundary-making in the neighbourhood (Fig. 4).

\subsection{Why Did a Project for the Promotion of Inter-group Relations Lead to a Conflict?}

The Intercultural Garden conflict in Nuremberg-Langwasser is a case of unintended consequences of social action, whereby a project that was intended to promote inter-group relations, mutual tolerance and cooperation, actually led to an ethnic neighbourhood conflict.

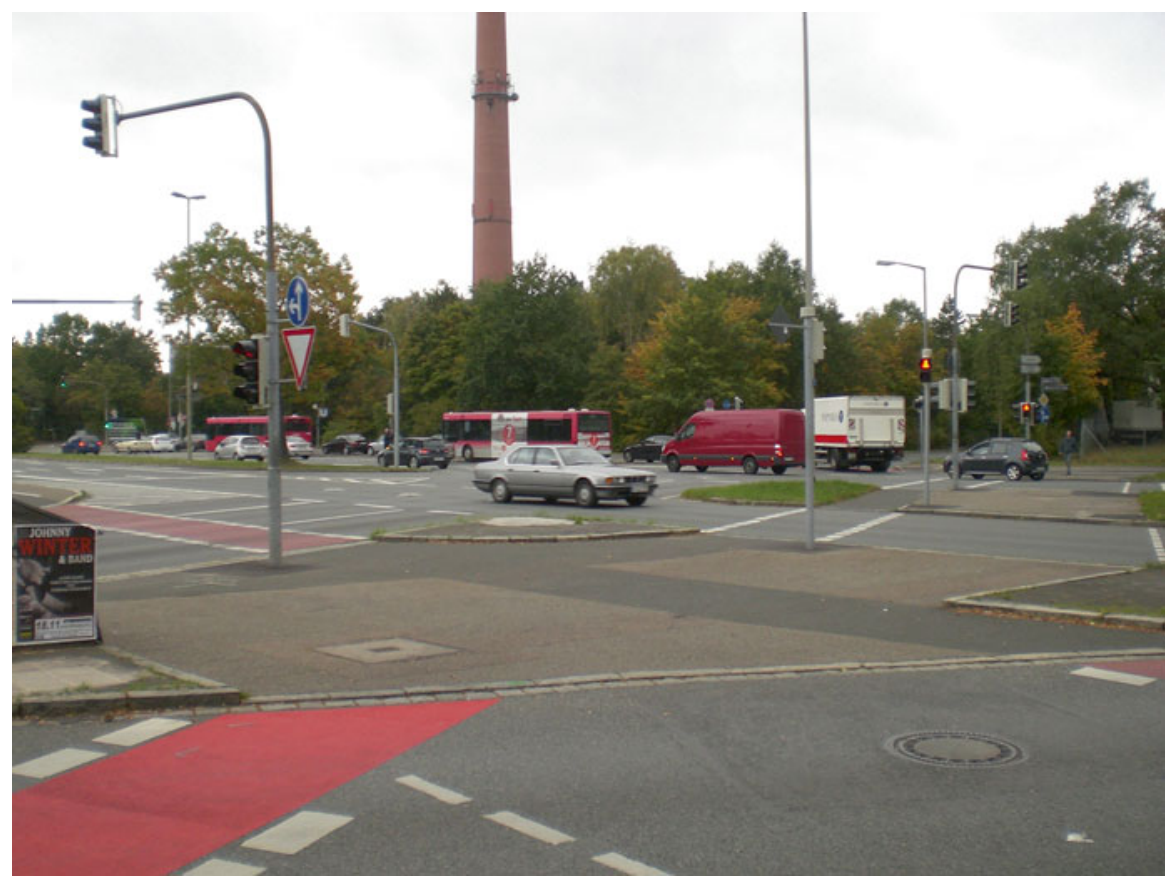

Fig. 4 Main square separating the four sectors of Langwasser (Photo by L. Batrla) 
Intercultural Gardens are gardening projects developed with the purpose of fostering the positive framing of diversity and intercultural learning and understanding and in doing so, fostering integration in the neighbourhood. The concept and the practice of Intercultural Gardens originated in the US and have been transplanted in a number of cities across Europe.

People of different origins, including native German, attend to their own small vegetable and flower patches (around $25 \mathrm{~m}^{2}$ ) in such gardens. There are no fences between neighbours; this is intended to encourage them to talk to each other about gardening and everyday issues. The goal of this exchange is to get to know each other, to diminish fears of contact, to develop mutual tolerance and respect, and even to promote friendships (Interkultureller Garten Nürnberg Langwasser e.V. 2010).

The quality of a city's integration policy has become a major indicator of a city's overall political competence and is a factor in its attractiveness to foreign migrants. Since Intercultural Gardens had been reported to be a successful method for improving inter-group relations between migrants and native majority, Nuremberg's integration policymakers took the decision to install such a garden as well in 2008 (Fig. 5).

\section{Insufficient Involvement of Residents and Subsequent Fears Lead to the Development of a Structural Conflict}

A site in the neighbourhood, which has a substantial share of inhabitants with a migration background and lots of green space, was chosen in the summer of 2009. The site was part of a park-like area, but close to multi-storey apartment buildings. City community workers set up a committee for the establishment of the garden, consisting of neighbourhood associations and individuals. The district coordinator held a meeting to inform the neighbourhood about the Intercultural Garden project that was about to be established nearby. The meeting was not well attended. During the meeting some residents in the neighbourhood of the site expressed fears about the project and disagreed with it.

One interviewee comments:

They are putting something there and I was not asked before, so my first reaction is objection. (Langwasser, director of neighbourhood association, 50 years old)

And another one firmly declares:

We don't need this, so we are against it. (Langwasser, director of neighbourhood association, 50 years old)

The fears were based on feelings that the garden would be too close to their houses, that gardeners would make noise, produce garbage and dirt, that parking space would become scarce, that safety in the neighbourhood would decrease together with the value of their property. For several months, the meeting remained the only dissemination of official information about the project. In the meantime, 


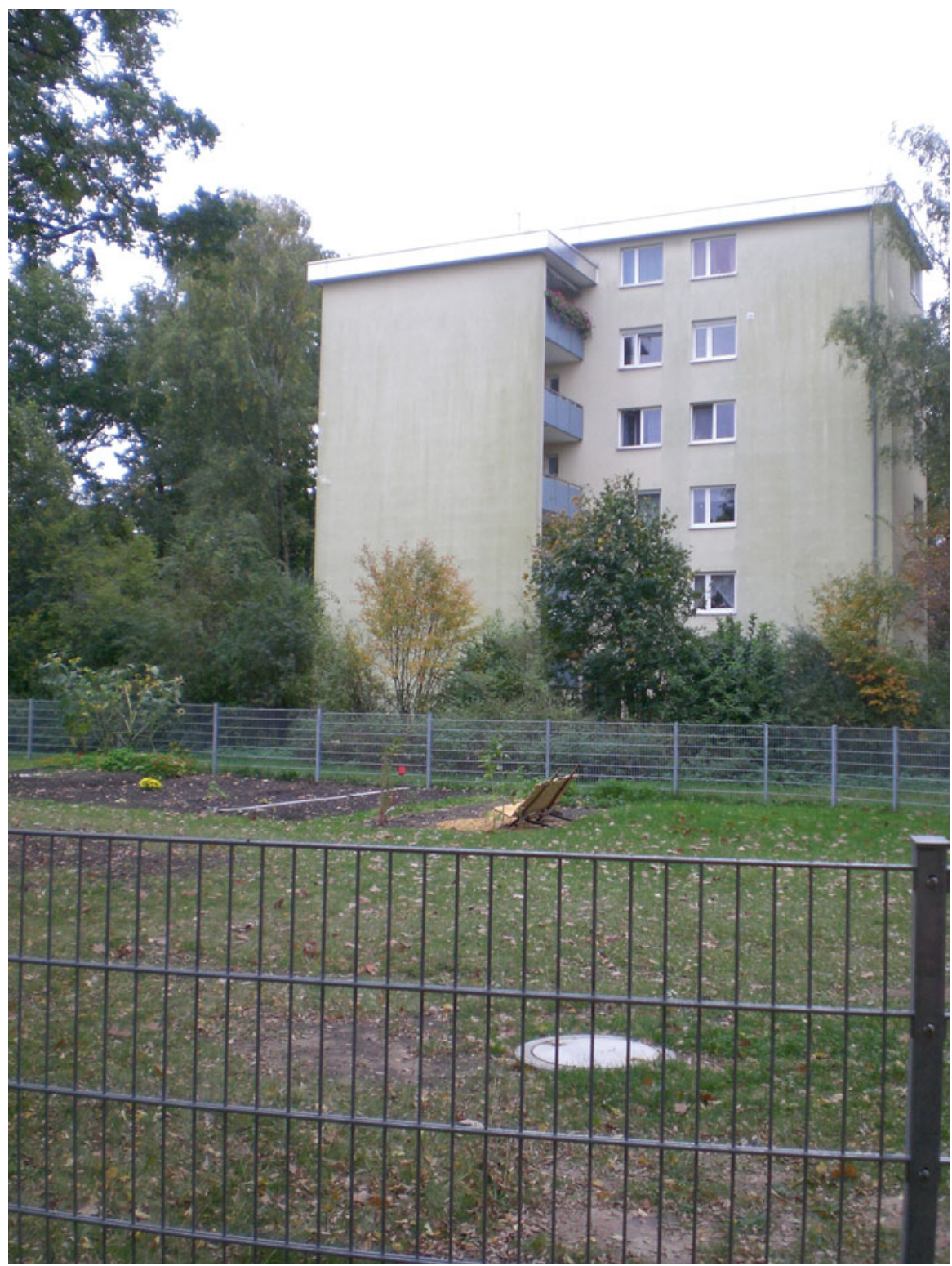

Fig. 5 Intercultural garden with neighbouring apartment building (Photo by L. Batrla)

rumours about the garden project were spreading in the neighbourhood. Residents felt there were similarities in the city's proceedings in the garden project and the recent process of planning and building a nearby sports park that was carried out without properly informing the neighbours. People felt 'run over' by the city's approach and the media sided with the residents' complaints. 
The structural conflict that ensued was driven by the residents' desire to keep their environment intact and unchanged and to maintain control over it. In their perception, they had a kind of legitimate right to control the surroundings of their houses. This was in conflict with the city's planning sovereignty to choose a site for developing a project at a location that seemed appropriate for it. The conflict was kindled by the residents' recent frustrating experiences with the construction of the sports park.

\section{Right-Wing Activists Contribute to the Framing and Ethnicization of the Conflict}

In this situation a neighbour of the planned garden site with right-wing political preferences started a campaign among residents of Langwasser and neighbours of the project site based on collecting signatures against the Intercultural Garden. As a result, the Intercultural Garden was increasingly considered by residents to be a project for migrants; few people realized that the project was intended for people with a migration history and residents of native origin to meet and better get to know one another. The residents' perception was further reinforced by anti-immigrant right-wing activists from outside Langwasser who intervened, putting up banners against the garden and distributing leaflets against the project. The different activities succeeded in defining the conflict as a migrant-majority conflict. The potential gardeners were portrayed as migrant intruders into the peaceful environment of the local residents, who did not respect the property rights of residents.

\section{Mobilization Turns into Counter-Mobilization}

The framing of the conflict as a migrant-native conflict had strongly emotionalized and politicized the case and drew more people into it, hence ethnic boundaries were reinforced in this stage. The person who started the signature campaign decided to file a lawsuit against the project and received a great deal of support from Langwasser residents and project neighbours. However, the residents supporting this lawsuit seemed to be largely unaware of its right-wing background. The majority of them withdrew their support when they became aware of who they were supporting:

In the meantime, they publicly distanced themselves from it [the support of the right-wing argumentation]. They were quite shocked, when they found out who they were sitting next to in the hearing [of the lawsuit]. All of a sudden, they were placed in the right-wing corner. Many of them were shocked. They did not like being associated with this at all. (Langwasser, director of neighbourhood association, 50 years old)

This indicates a case of unintended positioning where people were not fully aware of the nature of the cleavage they were associating with.

In this situation the district coordinator held a second public meeting to inform residents about the planned garden and to counteract the many rumours about the 
project. She also appealed to the media not to give the anti-immigrant groups publicity and support for their propaganda.

The media became increasingly critical of the right-wing campaign and reported more favourably about the project. In early 2010, a counter-mobilization set in with political parties and district organizations lending increasing support to the garden project. To counteract the fears of residents, the Intercultural Garden committee developed a set of rules to protect neighbours from possible disturbances, particularly referring to opening hours, parties, hygiene, parking and other provisions all of which were intended to prevent problems for the neighbours of the garden. These rules provided a basis for peaceful coexistence of gardeners and neighbours.

Because of the politicization and unwanted publicity only a rather small number of families (12) applied to have a lot in the garden and signed up.

\section{Right-Wing Agitation Loses Sympathisers, Garden Project Gains Sympathisers: A Conflict Solution Develops}

Two critical events are mainly responsible for the solution of the conflict: during a council hearing in the city hall heavily attended by residents from Langwasser, these residents began to realize that they were being misused by right-wing antiimmigrant neo-Nazi groups. Media reports about the hearing helped to change the perception of the garden conflict. People started disengaging from the campaign against the project. The other critical event was a decision of a local court dealing with the lawsuit against the garden. The court clearly rejected the lawsuit as unjustified and this took away much of the legitimation of the campaign and weakened the movement against it. The involvement of right-wing parties also had another kind of boomerang effect as it pushed associations and political parties to clearly take position for the project in order not to support the right-wing agitation in any way. All of these actors wanted to avoid being accused of sympathising with right-wing opinions due to their reluctance to take sides. In the meantime, an association for the garden had formally been established and a few months later the construction of the garden began. Tensions eased and in 2012 the garden association had 22 members with 18 active gardeners from 9 different countries. The gardeners are very careful to keep the garden clean and to give neighbouring residents no reason for complaints. In this scenario, the integration process, which had been temporarily hindered by the neighbourhood conflict, can continue.

The analysis of the series of events shows how residents generally do not want a 'new neighbourhood' to be forced upon them; instead they want to be involved in planning the change of their environment. The initially insufficient involvement of residents was one of the triggering factors of the conflict in the analyzed case. The later support from the media and the strong support from the policy community of Langwasser contributed considerably to the easing of the conflict. The case study illustrates the high relevance of the media and of policy actors for inter-group relations and for the resilience of a neighbourhood to right-wing agitation. 


\subsection{The Policy Community in Langwasser: Mediating Functions}

The policy community in Langwasser can be considered as quite diverse and well structured. A well-organized network of associations work with welfare organizations, youth centres, neighbourhood centres and municipal institutions such as the youth office and the social office. The district coordinator was recently replaced by a coordinating board. The cooperation of the neighbourhood actors and other neighbourhood activities are coordinated by the coordinating board. The well-functioning policy community makes a valuable contribution to inter-group relations in the neighbourhood. The impact of that contribution emerged with particular evidence in the responses to the conflict around the Intercultural Garden. A large number of associations and institutions joined together in that conflict led and coordinated by the district coordinator, in rejecting the involvement of right-wing groups and the ethnicization of the conflict, and at the same time supported the project of the Intercultural Garden as a valuable means for fostering inter-group contact and connections in Langwasser.

\section{High Cultural and Ethnic Diversity: Gostenhof}

Gostenhof is one of the most culturally and ethnically diverse neighbourhoods in Nuremberg. This traditional working-class neighbourhood is located near the city centre and is characterized by high housing density. This analysis focuses on the main street (Gostenhofer Hauptstrasse) where a large variety of shops and gastronomy can be found, most of them owned by people with a migration background (Fig. 6).

\subsection{The Function of Places: The Main Street as 'the' Place for Interactions}

In the following sections, we analyze the function of different types of places for inter-group relations in Gostenhof. Housing appears to connect people but also lead to insecurities: the relatively cheap housing units combined with the proximity to the downtown area attract artists as well as families with lower incomes, including a large number of migrants. The synergies which result from the mingling of these groups are part of the peculiarities of the neighbourhood. Moreover, the high density of the neighbourhood contributes to frequent contacts. In this sense, one interviewee asked 'How can I not be in contact with others in Gostenhof?' (Gostenhof, entrepreneur, 38 years old), indicating that contacts are unavoidable given the structure of the neighbourhood. However, housing is also a factor of fears in Gostenhof: due to the age and condition of buildings, renovations have been necessary. This has 


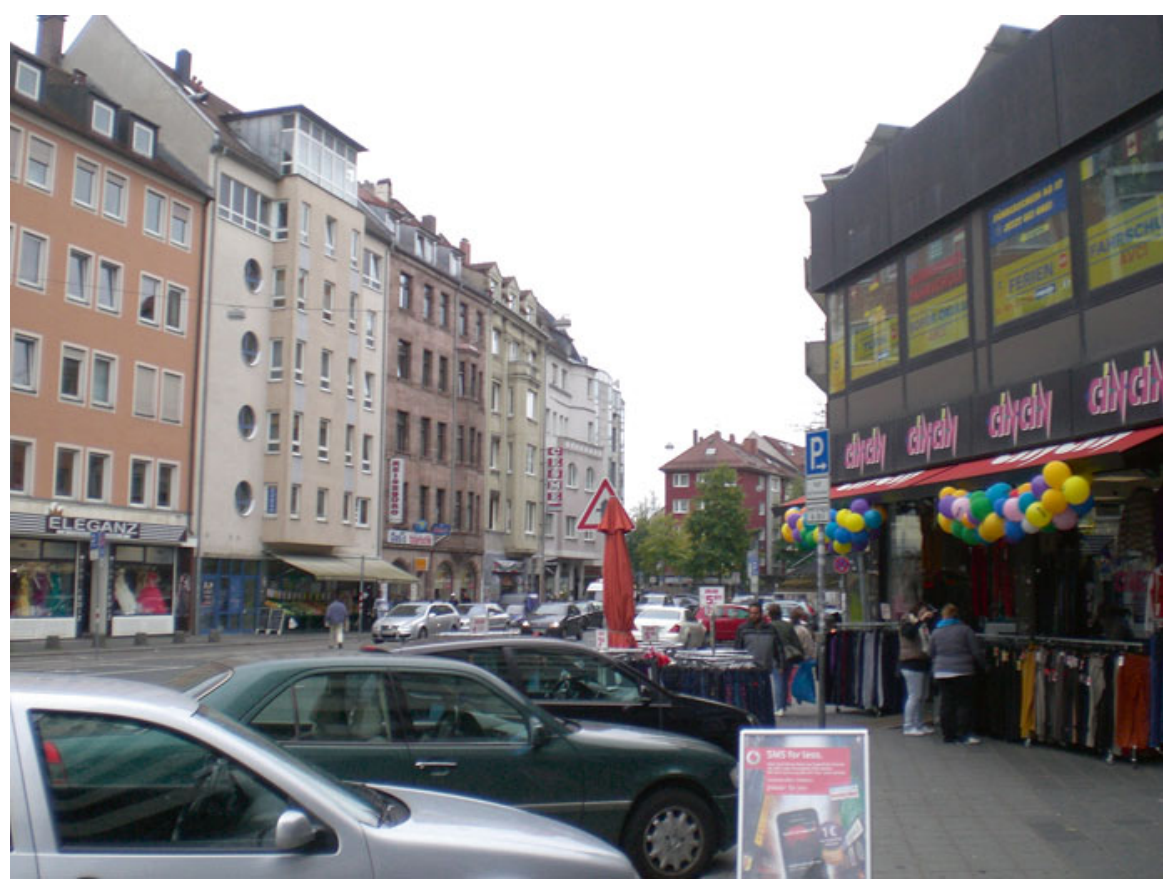

Fig. 6 Main street of Gostenhof (Gostenhofer Hauptstrasse) (Photo by L. Batrla)

led to an increase in quality of life but also in rents. Due to this development, some residents have had to move out and others are afraid they will have to do so in the future. Non-profit associations and other activity groups, as well as artists, are expected to be particularly affected by the rising rents. As a reaction to this development, some left-wing activists, among others, have been spraying graffiti in order to keep up the 'grubby' image of the neighbourhood.

Regarding public places in Gostenhof, the texture of the neighbourhood lacks green spaces and open areas (e.g., parks and playgrounds) and related opportunities of meeting in public. Although interviewees confirm this, they also describe a neighbourhood rich in social life and contact opportunities. Certain squares have become regular meeting places and festivities are frequently organized in backyards. At the same time, organizations offer regular events for social encounters in their venues. The variety of international stores, especially Turkish stores, in the main street (Gostenhofer Hauptstrasse), attracts people from inside and outside the neighbourhood and they have thus developed into places where connections can be made. Residents turn places not initially intended as meeting places into such, and hence assign a social function to them through their perception and habits. In line with this finding, public space in general, and shopping and leisure time facilities in particular, emerge from the ethnography as spaces of frequent and positive encounters between groups with different backgrounds (Fig. 7).

Moreover, schools and workplaces clearly emerge from our ethnography as zones of frequent and positive interaction between groups. The shared interests that 


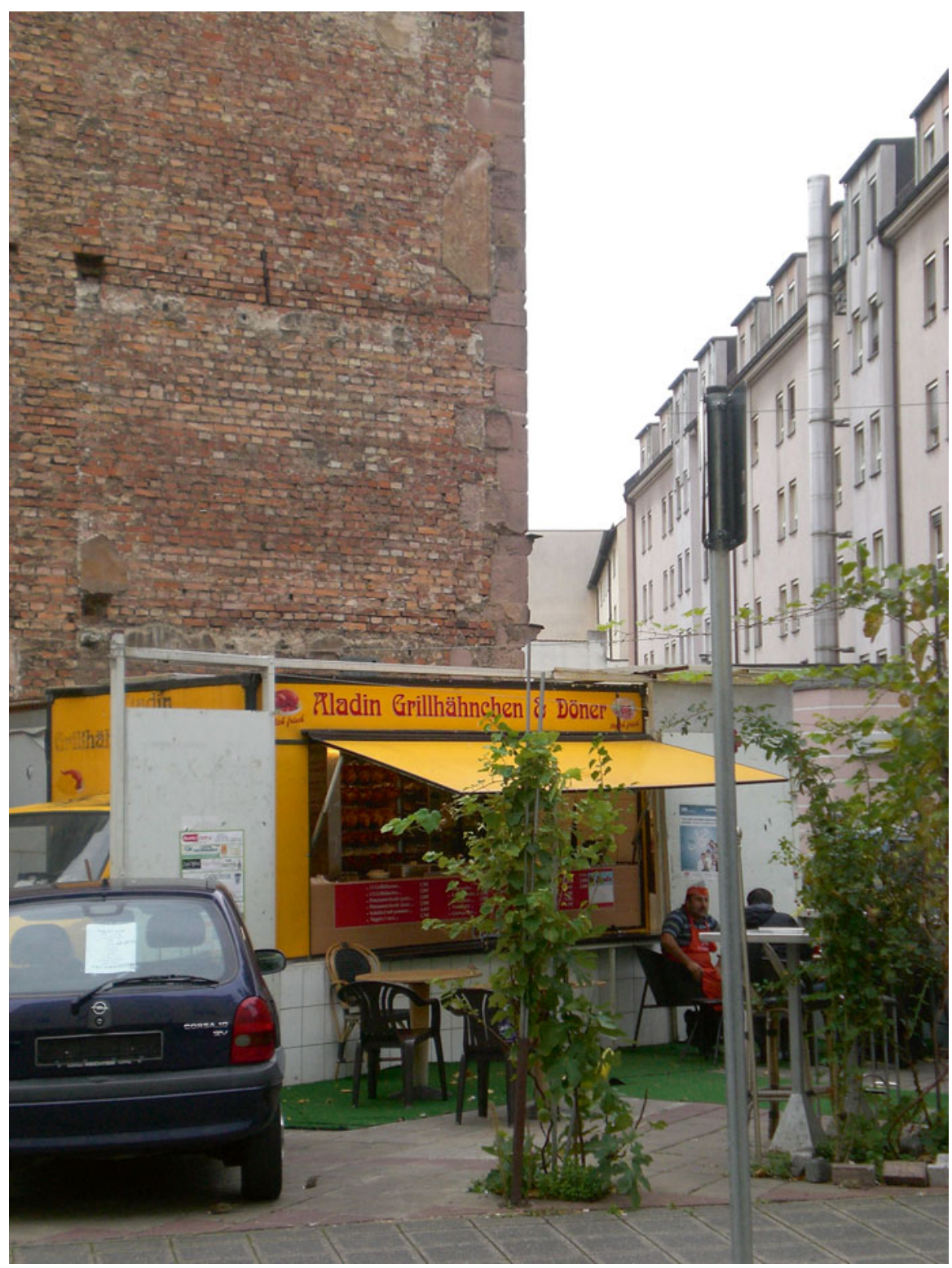

Fig. 7 A fast food stand at the corner of Gostenhofer Hauptstrasse that has gained the function of a popular meeting place (Photo by L. Batrla)

are associated with these zones seem to foster interactions. In Gostenhof, in stressing the irrelevance of the cultural background, interviewees consistently assert that shared interests are their main criterion for selecting the people they interact with. Hence, boundaries are constructed along lines of personal interest and characteristics rather than of culture. 
Besides their connecting function, the case of Gostenhof shows that zones of encounter can also be a source of fears: residents perceive the recent opening of numerous casinos around the main street as a serious social issue. These premises have been frequented mainly by people (both from majority and minorities) who live in difficult social circumstances. Gambling addiction is increasingly leading to problems in families within the neighbourhood. Interviewees consider it urgently necessary for the city to intervene and impose restrictions on these casinos in order to maintain the social peace in the neighbourhood.

\subsection{Social Relations and Diversity in Gostenhof: Migrants Are No Longer a Minority}

People of the most different origins, religions and perceptions are peacefully living together here. (Gostenhof, entrepreneur, 38 years old)

Gostenhof has a high proportion of foreigners among the total population (39.4 $\%$ in 2009) (Statistik Nürnberg Fürth 2011a) and an even higher proportion of residents with a migrant background. Native Germans are not a majority in the neighbourhood anymore, whereby the relevance of the majority-minority cleavage has nearly disappeared. More relevant cleavages are erected, among other criteria, along the lines of age and socio-economic status. The migrant population here is highly diverse and their size does not place them in the category of 'minority' anymore. On the contrary, the group of natives is in the process of becoming a minority itself. Some natives, especially those of the older generation, have fears of being part of a minority in the near future and some of them are considering moving out of the neighbourhood for this reason.

Among the young generation, ethnic boundaries appear to have lost relevance while other criteria, e.g., the identification with a territory, gain relevance. The analysis suggests that here, the relevance of 'other criteria' by far overweighs the relevance of ethnic boundaries. We find that particularly within groups of young people, the identification with the neighbourhood of Gostenhof and the city of Nuremberg is much more relevant than that of ethnic origin. In fact, young interviewees of Gostenhof refused to refer to ethnic or national origins when speaking about intergroup relations in the neighbourhood, arguing that these criteria do not matter to them or impact interactions in the neighbourhood in general. Among the young generation in Werderau and Langwasser there are tendencies towards this approach, but it is not as explicit as in Gostenhof.

Similar to the other neighbourhoods in Nuremberg, children in Gostenhof are in some contexts a marker of ethnic groupings and in others a bridge to inter-group relations. The bridging function finds confirmation in the high relevance of the school for contacts and interactions, whereas, in spite of the overall high appreciation of cultural diversity and cosmopolitanism in Gostenhof, we find a particular group of natives who seem to have 'double standards.' These families intentionally move to Gostenhof because of the above-mentioned attributes but send their children 
to schools out of the neighbourhood in order to avoid Gostenhof's schools which have a high proportion of migrants and a reputation for low- quality education. Parental school choices for their children in this case tend to enforce ethnic boundaries.

Religion in the context of religious and cultural diversity is perceived as enrichment and an opportunity for mutual exchange and learning in Gostenhof. This exchange and learning appears to be bearing fruit, as minorities perceive people from the majority as competent and experienced in communicating and interacting with people of different religious and cultural backgrounds. In this sense, one interviewee describes:

The people here know how Jews or Muslims celebrate their festivities. This is the peculiarity of Gostenhof. (Gostenhof, entrepreneur, 38 years old)

Socio-economic status and education appear to be relevant identification criteria in Gostenhof, where middle-class intellectual families are identified as a group, as opposed to those with a lower social and educational status. Both groups are represented in the neighbourhood for different motives: the latter group represents the original population base of Gostenhof, a traditional working-class neighbourhood with low housing prices. However, over the years, the state of the buildings deteriorated and with it the reputation of the neighbourhood. In order to improve both reputation as well as quality of living of the neighbourhood - the city initiated extensive renovation measures. Consequently, middle-class intellectual families were attracted by the combination of modern renovated apartments, the proximity of the neighbourhood to the downtown area and the rich and vivid social and cultural life of the neighbourhood. These two groups - both composed of majority and minorities members - appear to have little contact with each other. Education as such is described as a crucial factor for inter-group relations in Gostenhof: more highly educated people are generally perceived as 'the easiest to get along with' (Gostenhof, policymaker and resident, 41 years old), regardless of their origin.

The occupational field seems to be a further relevant cleavage. This is particularly the case when a certain occupational field is highly represented. We find this phenomenon in Gostenhof, where there are numerous artistic venues and shops, many of them owned by people with a migrant background. The groups of artists and shopkeepers are here identified as groups who tend to socialize within their own group.

\subsection{The Policy Community: Contributions to the Positive Image of Gostenhof}

In Gostenhof, we find a strong and well-represented policy community with strong support from both the district coordinator and the city of Nuremberg. The rich and diverse network of associations and social institutions is supported by the engagement of the district coordinator. The Neighbourhood Centre in Gostenhof is a 
central space for social life: many associations, including a large share of migrant associations, have their coordinating office in this building. Facilities such as meeting rooms can be used by all associations. Hence, the Neighbourhood Centre is a place where people come together in a cooperative manner, and where contributions to the rich social life in Gostenhof are made. The positive narrative in this sense contributes to the positive perception of inter-group relations inside and outside of the neighbourhood. At the same time, policy interventions contributed to an improvement of the reputation of the neighbourhood: due to the old building structure and the social challenges of the neighbourhood, its reputation used to be rather negative. Following targeted pressure by neighbourhood-level policy makers, the city took the decision to intervene through large-scale renovation projects which contributed to improving the neighbourhood's overall reputation.

It appears that the strong policy community with the well-organized network of associations and positive framing of policies, in combination with the high diversity of Gostenhof's population, make the neighbourhood more resilient to exogenous xenophobic influences than other neighbourhoods.

\section{Lessons Learned from the Neighbourhood Analysis}

In investigating places in the context of inter-group relations in the three neighbourhoods in Nuremberg we found two main functions of space: space can connect people and lead to interactions, but it can also be the object of disputes and conflicts. The same space can have both functions at the same time, but in different contexts. For the prevention of conflicts, frameworks of rules that are jointly agreed upon are essential.

The two functions of space as well as the high relevance of the rules for the use of space were found with regard to housing and the use of public places: housing as such, depending on how it is arranged, carries the potential of bringing people together and fostering interaction, but it can also be the object of conflicts, as analyzed in the case study of Werderau. We find that the rules on the use of space, as a result of social productions and perceptions, are more relevant for the actual use of public spaces than the existence and availability of these spaces as such. The extent to which the connecting potential of public spaces can be taken advantage of depends much on the rules of their usage. Clear and joint agreements on these rules as well as their communication to all people concerned are necessary to prevent potential conflicts.

The case studies of Werderau and Langwasser illustrate that conflicts over space can turn into ethnically framed conflicts. The overlapping of length of stay and ethnic belonging as well as external interference, e.g., by right-wing groups and biased media reportage, are identified as enabling factors of this ethnic framing and as enforcing factors for boundary-making. Mediation activities are often an effective tool to ease ongoing conflicts. 
Zones of encounter were found to be of particular relevance for connecting people and fostering targeted and deeper interactions. In such zones, people get together for a particular purpose and they share at least one field of interest. Additionally, rules of interaction are quite fixed in these zones and persons with mediating functions are mostly present. These elements are identified as facilitators for social and inter-group interactions. However, positive and frequent interactions within zones of encounter do not necessarily mean that the same people interact in the same manner in other places. Particularly in the cases of Werderau and Langwasser, the public space was not found to be very relevant for encounters between different groups. We assume that in these neighbourhoods, inter-group relations rather tend to be limited to zones of encounter where people meet for a particular purpose. A different picture emerges in the case of Gostenhof: the public space here is found to be a relevant and actual context for positive encounters between groups. Hence, in Gostenhof, inter-group relations seem to be not limited to zones of encounter but are transferred to the public space.

In analyzing barriers and bridges to inter-group relations, we find that the cleavage between minority and majority groups takes on different shapes in the analyzed neighbourhoods. We found a strong correspondence between the construction of these groups and the composition of the population in the neighbourhoods. Intergenerational cleavages appear relevant and sometimes overlap with majorityminority cleavages. This is particularly the case in Werderau. For the identification of a group, as well as for its formation, the group size clearly emerges as an influential factor. Bigger groups are more precisely identified and formed than smaller groups. In the case of Germany, the largest migrant minority originates from Turkey; hence they are clearly identified as 'Turks', as in the neighbourhood of Werderau. Other groups, who are smaller in numbers, are instead identified by their region of origin: for example, people of African origin, being altogether few, are usually not identified by their country of belonging but the broader African origin. Moreover, we find cleavages within minority groups. These divisions result from the high diversity of minority groups themselves, especially of big minority groups such as Turks and their descendants.

Language proficiency and language usage may also represent a barrier for interactions and a cleavage between different groups. As such, they may - but not necessarily - overlap with minority-majority ethnic cleavages. From this point of view, one interviewee explains the situation in Werderau in these terms: 'In the neighbourhood of Werderau one understands only little, if one is not proficient in several languages.'

Among young generations, ethnic boundaries appear to have lost relevance while other criteria, e.g., the identification with a territory, have gained in relevance. The degree to which this process has taken place seems to depend on the local context. Whereas in some areas it is in an early stage, elsewhere the relevance of 'other criteria' by far overweighs that of ethnic boundaries.

In all three neighbourhoods, we find people who simultaneously associate themselves with different groups: they tend to identify with one group regarding some criteria, e.g., socio-economic status, age, national origin, and with another group 
regarding other criteria. For example a young man of Turkish origin may identify with the group of young people in his neighbourhood, possibly with the group of students of his school, with the group of Turkish people of the neighbourhood and also with the group of men. At the same time, group belonging can be ascribed, independent of what people 'feel' their identity is. This was illustrated by the example of Italians who live in Werderau but are perceived as 'Turkish' in generalizing Turkish origin to all ethnic minorities in the neighbourhood. Hence, group belonging cannot clearly be assigned but is dependent on the context. Group identities therefore carry the potential of connecting people and of representing boundaries and cleavages. Within and between these groups, we find various types of interaction, much dependent on the context and perceptions of their members.

On a general note, our findings indicate that the cleavage between ethnic majority and minorities remains relevant, depending on the context. At the same time, other cleavages are increasingly significant. The policy community is found to have a relevant impact on inter-group relations and the capacity to shape and disseminate narratives about them in a neighbourhood. In Nuremberg, the lowest institutional level is the City. In selected neighbourhoods, generally those facing social challenges, the City appoints district coordinators ('Stadtteilkoordinatoren'). These ad hoc institutional figures play both a 'horizontal' and a 'vertical' role: their function is, on the one hand, to better connect institutions and actors on the neighbourhood level for the improvement of structures and services. On the other hand, they are also charged with facilitating stronger links between the neighbourhood and the city and with placing neighbourhood issues on the City agenda. The related activities of these district coordinators were found to be meaningful for inter-group relations and for channelling positive narratives about these relations in the three investigated neighbourhoods.

In regard of the central topic of the chapter - neighbourhood conflicts within integration processes - it can be noted that both of the conflicts identified in Werderau and Langwasser represented barriers for integration processes in the stages of the 'framing and ethnicization' and the 'mobilization and intensification of the conflict'. In the case of Werderau, previous progress in neighbourhood integration was even reversed in these conflict stages. In both cases, the stage of 'conclusion of the conflict' brought stakeholders and residents of the neighbourhoods closer together, thereby enabling cooperative action. In the case of Langwasser, this stage was successful because of the strong policy community whereas in Werderau this stage gave rise to the development of a policy community. However, in both cases, the conflicts could have been prevented through early policy interventions whereby neighbourhood integration could have progressed without barriers. In Gostenhof, a strong policy community has been in place and is identified as one of the enablers for well-functioning integration and positive inter-group relations in the context of high diversity. In this regard, we have been able to identify the following policy implications:

To conclude, we can affirm that there is a potential for conflicts to arise when sudden changes occur within the environment which residents of a neighbourhood have become used to. In our case studies the determining factors have been the 
following: (a) a lack of early information to notify residents of the planned changes caused rumours and fears leading to objections against the plans; (b) a lack of communication with and inclusion of the residents regarding the planned changes caused residents to feel excluded and ignored in their rights and concerns, leading to objections against the plans; (c) reluctance of the city administration to consider the concerns of residents and take action where necessary, leading to mobilization processes. When structural conflicts were framed in ethnical dimensions, determining factors appear to be ascriptions from outside of the neighbourhood, especially by right-wing forces. These forces seem to be particularly successful in contexts of residents' uncertainties, with a lack of intervention by the policy community and a strong established order.

Open Access This chapter is distributed under the terms of the Creative Commons AttributionNoncommercial 2.5 License (http://creativecommons.org/licenses/by-nc/2.5/) which permits any noncommercial use, distribution, and reproduction in any medium, provided the original author(s) and source are credited.

The images or other third party material in this chapter are included in the work's Creative Commons license, unless indicated otherwise in the credit line; if such material is not included in the work's Creative Commons license and the respective action is not permitted by statutory regulation, users will need to obtain permission from the license holder to duplicate, adapt or reproduce the material.

\section{Bibliography}

Beyer, A. (1990). Die Werderau: Sozialer Siedlungsbau des Architekten Ludwig Ruff von 1909 bis 1934, Band 2. Erlangen/Nuremberg: University of Erlangen-Nuernberg.

Esser, H. (2000). Soziologie: Spezielle Grundlagen. Band 2: Die Konstruktion der Gesellschaft. Frankfurt/New York: Campus.

Foth, W. (1943). Soziale Chronik aus 100 Jahren MAN. Ms. Nuernberg 1943. Nuremberg (MAN Archive).

Kötter-Anson, B. D. (1936). 25 Jahre Gartenstadt Werderau 1911 bis 1936: Für Angehörige der Maschinenfabrik Augsburg-Nürnberg AG. Nuremberg: Privatdruck.

Kraus, W. (Ed.). (2006). Schauplätze der Industriekultur in Bayern. Regensburg: Verlag Schnell \& Steiner GmbH.

Pastore, F., \& Ponzo, I. (2013). Concordia Discors: Understanding conflict and integration outcomes of inter-group relations and integration policies in selected neighbourhoods of five European cities. Synthesis report, Mar 2013.

Sherif, M., \& Sherif, C. W. (1969). Social psychology. New York/Evanston/London/Tokyo: Harper and Row and John Weathermill.

Smutny, R. (2004). Die Werderau in Nürnberg. Territoriales Verhalten in einer im Wandel befindlichen Werkssiedlung. Erlangen/Nuremberg: University of Erlangen-Nuernberg.

Wood, P., \& Landry, C. (2008). The intercultural city: Planning for diversity advantage. London/ Sterling: Earthscan. 


\section{Online Sources}

Interkultureller Garten e.V. (2010). Was ist ein Interkultureller Garten?www.stadtteilgartenlangwasser.de/index.html

Referat für Jugend, Familie, \& Soziales (2011). Projekte Stadtteilprojekt Werderau: bereits abgeschlossen.www.soziales.nuernberg.de/projekte/werderau.html

Stadtteilforum Langwasser. (2011). Aktuelles. stadtteilforum.org/langwasser/aktuelles.html

Statistik Nürnberg Fürth. (2010). Statistik aktuell für Nürnberg und Fürth, Statistischer Monatsbericht für Oktober 2010, M394, Nürnberg.www.nuernberg.de/imperia/md/sozialreferat/dokumente/sonstige_downloads/statistik_aktuell_2010_10_sozialraumanalyze.pdf

Statistik Nürnberg Fürth. (2011a). Statistisches Jahrbuch der Stadt Nürnberg 2010.www.nuernberg.de/imperia/md/statistik/dokumente/veroeffentlichungen/tabellenwerke/jahrbuch/jahrbuch_2010.pdf

Statistik Nürnberg Fürth. (2011b). Statistik aktuell für Nürnberg und Fürth: Statistischer Monatsbericht für Dezember 2010 (M 396).www.nuernberg.de/imperia/md/statistik/dokumente/veroeffentlichungen/berichte/monatsberichte/2010/statistik_aktuell_2010_12.pdf

Statistik Nürnberg Fürth. (2011c). Nürnberg facts \& figures 2011. www.nuernberg.de/imperia/md/ content/internet/ref7/wiv/factsandfigures_web.pdf

Statistik Nürnberg Fürth. (2012). Statistik aktuell für Nürnberg und Fürth: Statistischer Monatsbericht für Dezember 2012 (Teil 1, M 420).www.fuerth.de/Portaldata/1/Resources/ fuertherrathaus/monatsberichte-stats/2011-2012/Jahresrueckblick2012.pdf 